\title{
EDITORIAL
}

\section{Introduction to IJOHS}

Zainul Ahmad Rajion

Kulliyyah of Dentistry, International Islamic University Malaysia (IIUM)

It gives me great pleasure to write the foreword for the inaugural issue of the International Journal of Orofacial and Health Sciences (IJOHS).

The field of orofacial and health sciences is not static and the demand for studies addressing the large variety of current issues continues to grow. As an example, in medicine and dentistry, the planning and evaluation of maxillofacial surgery are dependent on advances in biomedical imaging for defining the underlying bony structures and their relationship to overlying soft tissue. Recently, the availability of state-of-the-art computed tomography (CT) has altered our approach to the analysis of complex craniofacial anomalies. Furthermore, the sophistication of medical imaging of the head and neck has advance significantly as a result of the marriage of computers and radiology and their close research collaboration between researchers and scientist, engineers and clinicians.

In view of this demand and the fact that numerous research findings published, there is a need for this journal, aims to bring together dentist, doctors and scientists, and other disciplines including computer expert and engineers to work together. Therefore, this journal hopes to create a medium for sharing ideas and importantly to provide a springboard for the application of multi-disciplinary and trans-disciplinary approaches with the common interest to share their knowledge and experience in many aspects of orofacial and health sciences. In addition to recognize, nurture and encourage scientific thinking that is required for the development and application of expanding biomedical knowledge and to foster scholarly interaction between them therefore contributing to the creation and improvement of sciences.

IJOHS is proud to launch its inaugural issue to keep informed of the activities and progress made. The editorial team believed that IJOHS will become the important source for the continuous research and commentary by offering an exceptional forum for the ongoing activities of the above professionals and to keep abreast of current trend and future developments.

We look forward to working together to achieve this important goal.

May I also take this opportunity to extend my grateful thanks to the Dean of the Kulliyyah of Dentistry, Dr. Salwana Supa'at for electing me as Chief Editor. 